\title{
Diagnostic Value of Procalcitonin in ANCA-Associated Vasculitis (AAV) to Differentiate Between Disease Activity, Infection and Drug Hypersensitivity
}

\author{
K. Herrmann ${ }^{*}, 1,2$, S. Schinke ${ }^{2}$, E. Csernok ${ }^{2}$, F. Moosig ${ }^{2}$ and J.U. Holle ${ }^{2}$ \\ ${ }^{I}$ Division of Rheumatology, Department of Medicine III, University Medical Center Carl Gustav Carus at the TU \\ Dresden, Dresden, Germany \\ ${ }^{2}$ Department of Rheumatology, Klinikum Bad Bramstedt, Germany
}

\begin{abstract}
Objective: Procalcitonin (PCT) is considered to be a specific marker for severe bacterial infections and sepsis. Elevated PCT levels have been reported in active autoimmune diseases without infection.

The aim of this study was to assess the diagnostic value of PCT serum levels in ANCA-associated vasculitis (AAV) patients with respect to infection, disease activity and drug fever using a high sensitive PCT detection method.

Methods: In 53 AAV patients with elevated C-reactive protein (CRP) PCT was determined by the Thermo Scientific BRAHMS PCT sensitive KRYPTOR assay. Patients underwent standardized diagnostic procedures for evaluation of disease activity and infection.

Results: 53 patients with AAV and elevated CRP $(7.7 \pm 6.9 \mathrm{mg} / \mathrm{dl}$, PCT $0.34 \pm 1.02 \mathrm{ng} / \mathrm{ml})$ were assessed, 10 had infection with elevated CRP levels of $11.2 \pm 10.2 \mathrm{mg} / \mathrm{dl}$ and PCT levels of $1.06 \pm 2.07 \mathrm{ng} / \mathrm{dl} .43$ patients had no evidence of infection, 36 of them were presented with AAV with normal or only slightly positive PCT levels in active disease ( $\mathrm{n}=36)(\mathrm{PCT}$ $0.06 \pm 0.06 \mathrm{ng} / \mathrm{ml}) .7$ patients had increased PCT levels due to azathioprine hypersensitivity $(0.76 \pm 1.01 \mathrm{ng} / \mathrm{ml})$. For discrimination between infection and vasculitis activity PCT was more useful than CRP with the best cut-off at $0.1 \mathrm{ng} / \mathrm{ml}$ (sensitivity $60 \%$, specificity $92 \%$ ).

Conclusion: In contrast to previous studies using semiquantitative PCT assays, the KRYPTOR performs better with respect to discrimination of infection from active AAV. In all patients assessed with active AAV (and without infection) PCT levels remained below the PCT reference limit $(0.5 \mathrm{ng} / \mathrm{ml})$ for infections. Drug hypersensitivity seems to be an important differential diagnosis in the setting of elevated CRP and PCT in patients who receive azathioprine.
\end{abstract}

Keywords: Active vasculitis, azathioprine hypersensitivity, infection, procalcitonin.

\section{INTRODUCTION}

Differentiating bacterial infections from disease activity is crucial in patients with autoimmune disease. Neither the clinical presentation nor markers such as C-reactive protein (CRP) or leukocyte count are helpful in distinguishing these two conditions. PCT, the precursor protein of calcitonin, is undetectable in healthy individuals $(<0.05 \mathrm{ng} / \mathrm{ml})$ and has been shown to increase rapidly in bacterial infections [1]. It has been suggested that PCT is not significantly increased in disease activity in various autoimmune diseases (AID) including Granulomatosis with Polyangiitis (GPA) and may therefore help to distinguish between AID activity and bacterial infections [2]. Other reports showed elevated PCT levels in active GPA [3, 4], Anti-GBM disease (formerly Goodpasture`s syndrome) [5], adult onset Still`s disease [6]

*Address correspondence to this author at the Division of Rheumatology, Department of Medicine III, University Medical Center Carl Gustav Carus at the TU Dresden, Fetscherstr. 74, 01307 Dresden, Germany;

Tel: +49-35145819377; Fax: +49-3514585801;

E-mail: kristine.herrmann@uniklinikum-dresden.de and Kawasaki disease [7]. So far, only small numbers of AAV patients (22 to 35 patients) have been studied with respect to their PCT levels [2-4]. A recent meta-analysis by $\mathrm{Wu}$ et al. [8] pointed out that in most published studies on PCT in AID a low-sensitive LUMItest was used. In only two studies, the most precise VIDAS was used and none of the studies investigated the most advanced assay KRYPTOR [8]. In order to clarify whether PCT has a role in discriminating between bacterial infection and disease flares in AAV, we examined PCT levels in AAV patients with elevated CRP measured by a highly sensitive assay, the Thermo Scientific BRAHMS PCT sensitive KRYPTOR assay. As elevated PCT levels have been described in single cases of drug fever due to carbamezepine [9] and mycophenolate [10], we aimed to assess PCT levels in the context of drug fever induced by azathioprine (AZT) which is the most frequently used maintenance treatment in AAV.

\section{MATERIALS AND METHODS}

Sera from 53 patients with biopsy proven generalized AAV and elevated CRP $(7.7 \pm 6.9 \mathrm{mg} / \mathrm{dl}$, normal $<0.5 \mathrm{mg} / \mathrm{dl})$ were analyzed. The diagnosis of GPA $(n=48)$, MPA $(n=4)$ or 
EGPA ( $n=1)$ was established according to the definitions of the Chapel Hill Consensus Conference and/or fulfillment the classification criteria of the American College of Rheumatology and/or the EMA algorithm [11]. The Birmingham Vasculitis Activity Score (BVAS 2003) served to assess disease activity. Patients with BVAS of zero were considered to be in complete remission. Infections were confirmed by the presence of a positive microbial test in blood, sputum, bronchoalveolar lavage, urine and by evidence of infection in imaging (Chest X-ray, abdominal ultrasound, MRI of nasal sinus when clinically indicated). In this study, we have distinguished between systemic, defined as detection of pathogens in the blood stream, and local or organ-limited infections. It needs to be considered that local infections can be serious (e.g. pneumonia). PCT levels were measured using a specific ultrasensitive commercial automated assay (Thermo Scientific BRAHMS PCT sensitive KRYPTOR assay, Berlin/Germany) with functional assay sensitivity of $0.06 \mathrm{ng} / \mathrm{ml}$. In order to relate PCT levels to vasculitis activity, sera of 13 GPA individuals were analyzed at times of active disease and in remission.
The analysis were conducted retrospectively from sera of the respective AAV patients. Statistical analysis was done using Wilcoxon test for matched pairs to compare active to inactive disease in 13 sera pairs including Bonferroni correction for multiple testing. A p-value $<0.05$ was considered statistically significant. To examine the differential diagnostic value ROC analysis was performed with GraphPad Prism5 between two groups, active AAV $(n=36)$ and infections $(n=10)$. The Youden-Index was chosen as cut-off for the ROC analysis.

\section{RESULTS}

53 patients with elevated CRP levels $(7.7 \pm 6.9 \mathrm{mg} / \mathrm{dl})$ were studied. These patients had a mean PCT level of $0.34 \pm 1.02 \mathrm{ng} / \mathrm{ml}$. In 24 of 53 patients, PCT was increased $(0.71 \pm 1.44 \mathrm{ng} / \mathrm{ml})$. These patients were further assessed for the presence of infection: In 10 patients (CRP 11.2 \pm 10.2 $\mathrm{mg} / \mathrm{dl}$ ) an infection was documented, and PCT levels were elevated $(1.06 \pm 2.07 \mathrm{mg} / \mathrm{dl})$. Infections were local in 8 patients and systemic in 2 patients; interestingly, patients

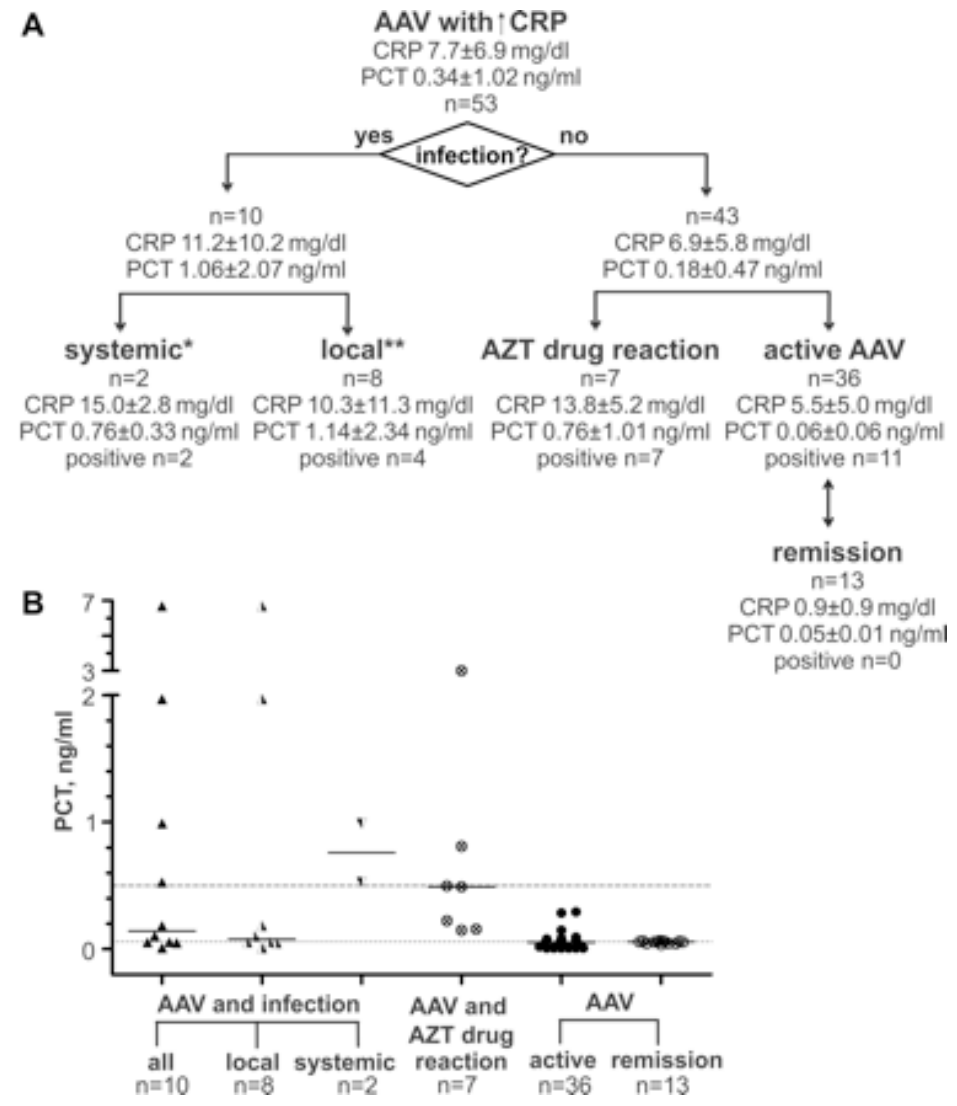

Fig. (1). A: Flowchart of analyzed AAV subgroups. CRP and PCT concentrations are represent as mean and standard deviation. Number of PCT positive samples is given for each subgroup. Additions to infection and causative pathogen: * -recurrent sepsis (blood culture: gramnegative rod-shaped bacteria; urin culture: klebsiella oxytoca);-respiratory sepsis, in course with multiorgan failure and exitus (bronchial lavage: multiresistent pseudomonas aeruginosa, candida albicans, aspergillus fumigatus; blood culture: enteroccus faecium) $* *$-atypical mycobacteriosis (bronchial lavage: M. avium, M. intracellulare complex);-pneumonia (bronchial lavage: staphylococcus aureus, haemophilus influenzae);-pneumonia (bronchial lavage: haemophilus influenzae); -pneumonia (sputum: escherichia coli, enterococcus faecalis, pseudomonas aeruginosa); -lacrimal duct abscess (MRSA); -serom of parotid gland (enteroccocus); -superinfection of pulmonal cavern (actinobacter and aspergillus); -superinfection of skin ulcus with concomitant lymphadenitis (proteus mirabilis, enterococcus faecalis, stenotrophomonas). B: PCT concentrations in AAV patients. Horizontal line indicates the defined limit for systemic infections at $0.5 \mathrm{ng} / \mathrm{ml}$ and functional assay sensitivity at $0.06 \mathrm{ng} / \mathrm{ml}$. Bars are medians. 13 of 36 AAV patients were assessed regarding CRP and PCT levels during active disease and remission. 
Table 1. Laboratory and disease activity data of 13 GPA patients with PCT assessment at active and inactive stage of disease (mean \pm SD). For ANCA titers medians are given. In 12 patients C-ANCA and in one patient P-ANCA were detected.

\begin{tabular}{|c|c|c|c|}
\hline & Active & Remission & Adjusted p-Value \\
\hline \hline BVAS & $18.15 \pm 7.2$ & $0 \pm 0$ & 0.0018 \\
\hline DEI & $7.46 \pm 3.2$ & $0.46 \pm 0.85$ & 0.0018 \\
\hline VDI & $0.62 \pm 1.26$ & $1.54 \pm 1.39$ & $0.0702 ; \mathrm{ns}$ \\
\hline CRP, $\mathrm{mg} / \mathrm{dl}$ & $6.08 \pm 6.19$ & $0.92 \pm 0.92$ & 0.0063 \\
\hline ESR, $\mathrm{mm} / \mathrm{h}$ & $62 \pm 31$ & $21 \pm 18$ & 0.0045 \\
\hline leukocytes/nl & $10.5 \pm 3.3$ & $6.9 \pm 2.9$ & $0.081 ; \mathrm{ns}$ \\
\hline PCT, $\mathrm{ng} / \mathrm{ml}$ & $0.07 \pm 0.07$ & $0.05 \pm 0.01$ & $4.5144 ; \mathrm{ns}$ \\
\hline creatinine, $\mathrm{mg} / \mathrm{dl}$ & $1.4 \pm 1.5$ & $1.1 \pm 0.4$ & $3.0024 ; \mathrm{ns}$ \\
\hline ANCA & $1: 1280$ & $1: 160$ & $0.0612 ; \mathrm{ns}$ \\
\hline
\end{tabular}

with systemic infections showed lower PCT levels than patients with local infections (Fig. 1). 43 patients had no evidence of infection, 7 of whom were diagnosed with azathioprine drug fever which as accompanied by marked PCT elevation (PCT $0.76 \pm 1.01 \mathrm{ng} / \mathrm{ml}$ ). 36 patients were diagnosed with active AAV. All of these patients had normal or slightly elevated PCT levels $(0.06 \pm 0.06 \mathrm{ng} / \mathrm{ml})$.

In 11 from 36 patients with active disease PCT was slightly above the functional assay sensitivity of $0.06 \mathrm{ng} / \mathrm{ml}$ $(0.12 \pm 0.09 \mathrm{ng} / \mathrm{ml})$, but not over the defined limit for systemic infections of $0.5 \mathrm{ng} / \mathrm{ml}$.

In 13 of 36 active AAV patients we could also examine PCT in serum at time of remission. In all samples PCT was below $0.06 \mathrm{ng} / \mathrm{ml}$. Of the 13 patients listed in Table 1, five patients presented with a PCT level $>0.06 \mathrm{ng} / \mathrm{ml}$ and eight with a PCT level $<0.06 \mathrm{ng} / \mathrm{ml}$ during active disease. See Table 1 for other clinical and laboratory parameters of these 13 patients at time of relapse and remission.

We also noticed that 16 of 24 PCT positive patients showed serum levels in the "grey area" between 0.06 and 0.5 $\mathrm{ng} / \mathrm{ml}$. These patients had various reasons for a PCT elevation: two patients were diagnosed with local infection, 3 with AZT drug reaction and the remaining 11 with an AAV flare.

In the local infections group there were two patients with pneumonia whose PCT values were within septic range (1.97 and $6.68 \mathrm{ng} / \mathrm{ml})$. In the same group, two patients with proven pulmonary infection in bronchial lavage (atypical mycobacteria; staphylococcus aureus) had PCT values below $0.25 \mathrm{ng} / \mathrm{ml}$.

Patients with systemic infections and AAV showed PCT above $0.5 \mathrm{ng} / \mathrm{ml}$. The highest PCT levels were noted in patients with infection $(n=4)$ and azathioprine drug reaction $(n=4)$ (Fig. 1B).

For discrimination between infection and vasculitis activity PCT was more useful than CRP. Analysis of discrimination (Fig. 2) suggests that PCT had a greater area under the ROC curve value $(0.75$ [95\% CI $0.55-0.94]$, $\mathrm{p}=0.017)$ compared with CRP $(0.67$ [95\% CI 0.46-0.88], p $\mathrm{ns})$. The best cut-off value to differentiate infection from
AAV flare for PCT (CRP) was $0.1 \mathrm{ng} / \mathrm{ml}(12.6 \mathrm{mg} / \mathrm{dl})$ with a sensitivity of $60 \%(50)$ and a specificity of $92 \%(95)$.

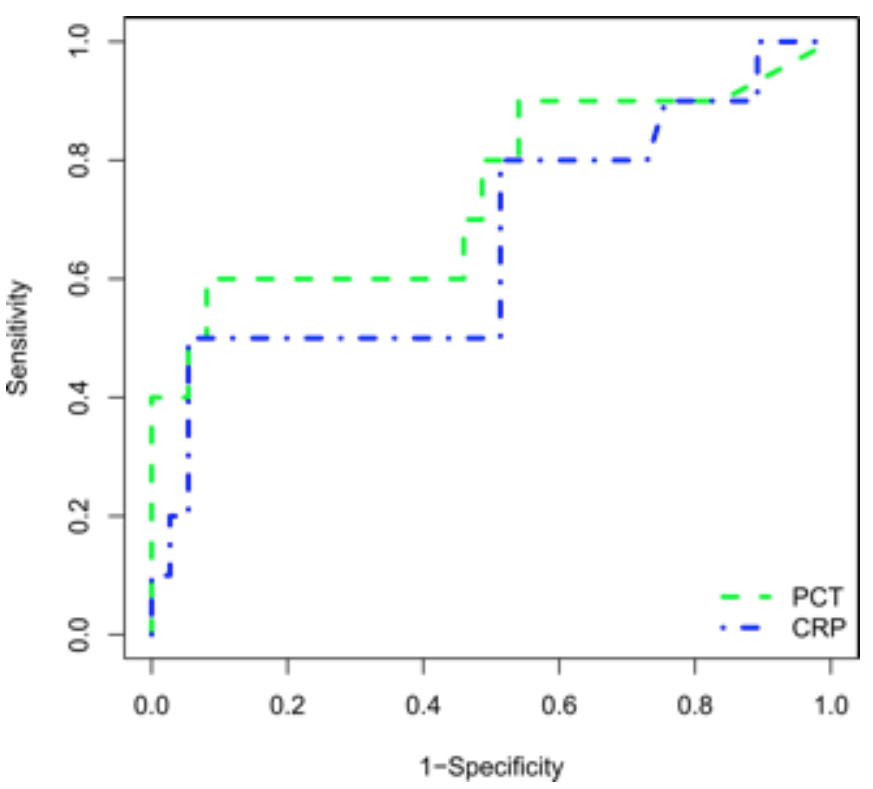

Fig. (2). Receiver operating characteristics (ROC) curve for CRP and PCT levels in differentiating bacterial infections $(n=10)$ from AAV flares $(n=36)$. The area under the curve (AUC) was $0.67[95 \%$ CI $0.46-0.88, \mathrm{p} \mathrm{ns}$ ] for CRP and 0.75 [95\% CI 0.55-0.94, $\mathrm{p}=0.017]$ for PCT.

Remarkably elevated PCT was also observed as an inflammatory drug reaction to AZT. Seven vasculitis patients (five patients with GPA, one patient with EGPA, one with MPA) were admitted to hospital with fever. All patients had been receiving AZT as maintenance therapy for three to 20 days before onset of fever (Table 2). The fever $\left(38-40^{\circ} \mathrm{C}\right)$ was accompanied by emesis, conjunctivitis, erythema nodosum, cough, syncope and pancreatitis. Six of seven had been classified as being in remission and one patient with aggravation of polyneuropathia suffered from an AAV relapse. All patients had high PCT levels $(0.76 \pm 1.0 \mathrm{ng} / \mathrm{ml})$ although there was no further clinical or other evidence of infection by microbial cultures or imaging. Consequently, a drug fever, which is a rare side effect of AZT, was diagnosed as all symptoms including fever ceased and laboratory parameters normalized immediately after stopping AZT. 
Table 2. Characteristics of patients with drug hypersensitivity reaction due to AZT. Organ involvement is given according to Disease Extent Index nomenclature.: A-joints; B-constitutional symptoms; C-central nervous system; E-ear, nose, throat; EY-eyes; GI-gastrointestinal; H-heart; K-renal; L-lung; M-muscle; P-peripheral nervous system; S-skin. * Maximal PCT and CRP values are given in course of drug reaction and not at the screening measurement with Kryptor assay.

\begin{tabular}{|c|c|c|c|c|c|c|c|c|}
\hline Patient & Gender & Age & AAV & $\begin{array}{l}\text { Previous Organmani- } \\
\text { Festation and Activity } \\
\text { Status of AAV }\end{array}$ & $\begin{array}{l}\text { Duration to } \\
\text { AZT Fever }\end{array}$ & $\begin{array}{c}\text { Body } \\
\underset{{ }^{\circ} \mathrm{C}}{\text { Temperature, }}\end{array}$ & $\begin{array}{c}\text { Maximal PCT/CRP } \\
\text { (ng/ml / mg/dl) * }\end{array}$ & $\begin{array}{c}\text { Additional Symptoms } \\
\text { Caused by AZT Drug } \\
\text { Reaction }\end{array}$ \\
\hline 1 & $\mathrm{~m}$ & 61 & GPA & $\mathrm{E}, \mathrm{L}, \mathrm{K}, \mathrm{A}, \mathrm{P}$ remission & 12 & 40.0 & $1.1 / 22.3$ & arthralgia \\
\hline 2 & $\mathrm{~m}$ & 73 & MPA & $\begin{array}{c}\mathrm{L}, \mathrm{B}, \mathrm{P}, \mathrm{A} \\
\text { partial remission }\end{array}$ & 10 & 39.0 & $12.6 / 11.4$ & emesis \\
\hline 3 & $\mathrm{w}$ & 70 & GPA & $\begin{array}{c}\mathrm{E}, \mathrm{L}, \mathrm{A}, \mathrm{B} \\
\text { partial remission }\end{array}$ & 12 & 41.0 & $2.1 / 10$ & \\
\hline 4 & $\mathrm{~m}$ & 32 & EGPA & $\begin{array}{l}\mathrm{E}, \mathrm{L}, \mathrm{S}, \mathrm{P}, \mathrm{C}, \\
\text { A,B,M } \\
\text { remission }\end{array}$ & 6 & 38.6 & $0.4 / 17.5$ & erythema nodosum \\
\hline 5 & $\mathrm{~m}$ & 65 & GPA & $\begin{array}{l}\mathrm{E}, \mathrm{L}, \mathrm{K}, \mathrm{P}, \mathrm{A}, \mathrm{B} \\
\text { remission P }\end{array}$ & 10 & 39.5 & $0.5 / 15.1$ & emesis, syncope \\
\hline 6 & $\mathrm{~m}$ & 49 & GPA & $\begin{array}{c}\text { E,L,K,P,EY, } \\
\text { S,A partial remission }\end{array}$ & 3 & 39.9 & $0.4 / 19.4$ & \\
\hline 7 & $\mathrm{~m}$ & 65 & GPA & $\begin{array}{l}\text { E,S,B,P } \\
\text { remission }\end{array}$ & 20 & 40.0 & $5.1 / 12.2$ & $\begin{array}{l}\text { Rhinitis, cought, } \\
\text { conjunc-tivitis, erythema } \\
\text { nodosum, lipase } 1516 \mathrm{U} / 1\end{array}$ \\
\hline
\end{tabular}

Activity of AZT degrading enzyme thiopurin-smethyltransferase (TPMT) was determined in 4/7 patients before AZT, but no gene mutations were detected. All patients were treated with paracetamol i.v., and some received i.v. rehydration. All recovered fast after stopping AZT.

One patient re-exposed himself accidentally to AZT after discontinuation of the treatment for two days and was hospitalized on the day of reexposure. Reexposure to AZT augmented PCT levels even further (Fig. 3).

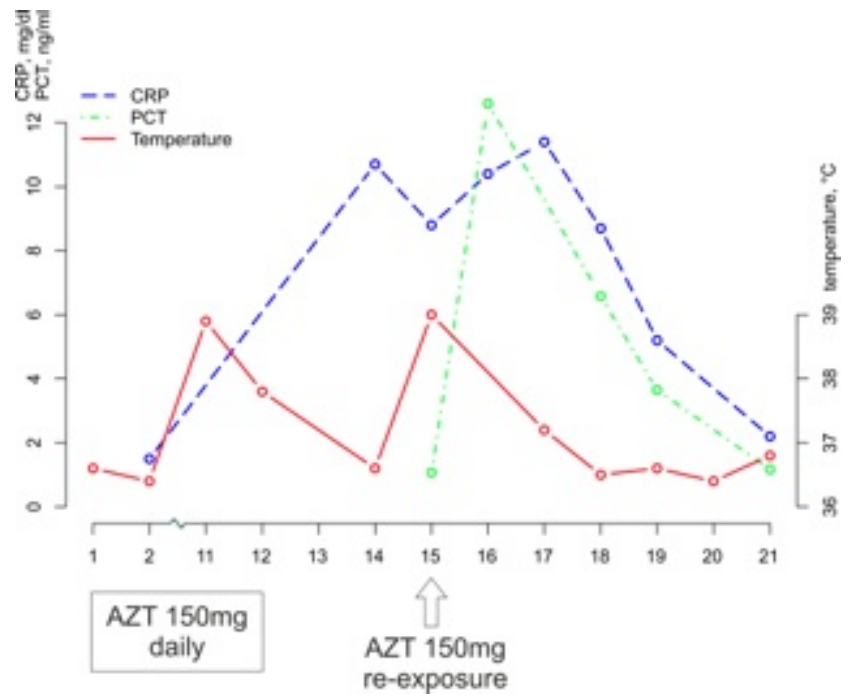

Fig. (3). Course of CRP, PCT and body temperature after stopping of AZT at day 12 and re-exposure at day 15 in one of the patients with AZT drug reaction.

\section{DISCUSSION}

PCT is regarded to be a specific marker of severe systemic bacterial and fungal infections and sepsis. The value of PCT measurement in AID is unclear as previous studies and case reports are heterogenous regarding methods and results [8, 12]. Most studies used PCT LUMItest, a semiquantitative test with a measurement range of 0.3-500 $\mathrm{ng} / \mathrm{ml}$. Therefore today, LUMItest is recommended only for diagnosis and monitoring of sepsis and not for mild infections [13].

This study assessed PCT in the context of infection, AID and drug hypersensitivity with the high sensitive generation PCT assay (KRYPTOR). We showed PCT elevation in AAV patients with mild local and systemic infections, which is in contrast to our previous report on LUMItest that detected PCT only in severe systemic infections [3]. The reason for its superiority is KRYPTOR's functional assay sensitivity of $0.06 \mathrm{ng} / \mathrm{ml}$ with a measurement range of $0.06-1000 \mathrm{ng} / \mathrm{ml}$ [14].

Previous studies found increased PCT levels in patients with vasculitis without evidence of infection [12], especially during severe vasculitis relapses such as renal or pulmonary involvement. Zycinska et al. [4] reported a mean PCT in active GPA of $0.58 \pm 0.85 \mathrm{ng} / \mathrm{ml}$. Moosig et al. [3] have shown that PCT levels rose to $0.8-3.3 \mathrm{ng} / \mathrm{ml}$ in highly active GPA ( $n=3$ patients), although it was also reported that in the vast majority of patients (23 of 26) PCT levels were within the normal range both in active and inactive disease. In our AAV cohort assessed by KRYPTOR we did not observe any PCT elevation above $0.5 \mathrm{ng} / \mathrm{ml}$ in non-infected active AAV 
patients. This applied even to the most severe vasculitis manifestations where only slightly elevated PCT with a mean $0.12 \pm 0.09 \mathrm{ng} / \mathrm{ml}$ were seen (3 severe pulmorenal syndrome, 2 nephrotic syndrome, 4 acute glomerulonephritides, 1 alveolar haemorrhage, 1 destructive ENT involvement with saddle nose formation). We cannot definitely rule out that marked PCT elevations may occur in some patients with very active GPA, yet we confirm our previous report [3] that in the majority of active GPA patients, a significant elevation of PCT does not seem to occur.

Joo et al. [15] demonstrated that PCT may be useful to differentiate between AID activity and bacterial infections using an enzyme-linked fluorescent assay VIDAS (bioMérieux): At a cut-off value for PCT of $0.09 \mathrm{ng} / \mathrm{ml}$, the assay had a sensitivity of $81.3 \%$ and a specificity of $78.7 \%$ for distinguishing flares from bacterial infections. Our results revealed a higher specificity of $92 \%$ and an expected lower sensitivity of only $60 \%$ at the optimum cut-off for PCT of $0.1 \mathrm{ng} / \mathrm{ml}$ which is lined up with other studies. The VIDAS assay used by Joo et al. [15] and KRYPTOR correlated remarkably well $(\mathrm{r}=0.962)$ with an overall concordance of $84.6 \%$ [16]. Joo et al. [15] studied a heterogeneous population with AID (only 2/79 with AAV) and infection was merely diagnosed on clinical grounds (only 14/32 with cultural evidence of bacterial infection).

Our results suggest that PCT has a greater area under the ROC curve value $(0.75$ [95\% CI $0.55-0.94], \mathrm{p}=0.017)$ compared with CRP (0.67 [95\% CI 0.46-0.88], p n.s.). This data need to be interpreted with caution due to the small sample size, the heterogeneity of the study cohort and the fact that patients were selected on the basis of an elevated CRP value.

In our study, 6/10 infected AAV patients had positive PCT levels $(1.74 \pm 2.5 \mathrm{ng} / \mathrm{ml})$. For discrimination between infection and vasculitis activity, the best cut-off in this study is at $0.1 \mathrm{ng} / \mathrm{ml}$ (sensitivity $60 \%$, specificity $92 \%$ ).

Interpretation of borderline PCT levels between 0.06 $\mathrm{ng} / \mathrm{ml}$ and $0.5 \mathrm{ng} / \mathrm{ml}$, remains difficult in the immunocompromised patient, as it cannot be distinguished if the inflammatory activity is due to AID or is due to concomitant infection.

Furthermore the immunosuppressive treatment might inhibit PCT elevation. Although the production of PCT was not attenuated by corticosteroids in one study [17], the influence of other immunosuppressive drugs has not been investigated.

Moreover one has to consider that in immunosuppressed patients, the acute phase reaction might be downregulated and therefore PCT might be false negative in mild infections [18]. This might also explain why our four patients with local infections such as lacrimal duct abscess (MRSA), serom of parotid gland (enteroccocus), superinfection with actinobacter/aspergillus of pulmonal cavern and superinfection of a skin ulcus with concomitant lymphadenitis (proteus mirabilis, enterococcus faecalis, stenotrophomonas) showed no elevated PCT.

From the observations in this study, PCT values above $0.5 \mathrm{ng} / \mathrm{ml}$ indicate the presence of infection. In accordance with other studies, we confirm that PCT values above 0.5 $\mathrm{ng} / \mathrm{ml}$ indicate the presence of infection.

Whether or not a different cut-off level of PCT for invasive infections in AAV patients (i.e., $>1 \mathrm{ng} / \mathrm{ml}$, as proposed by Schwenger, reviewed in [12]) should be used which remains unproven and needs further study. In our study, we did not have enough patients with invasive infections, to verify this statement. In non-infectious conditions elevated PCT levels ("false positive PCT") can be found in various conditions [19-26], including severe drug reactions such as the drug reaction with hypereosinophilia syndrome (DRESS) due to carbamazepine $[9,27]$ and to mycophenolate [15].

We show for the first time that AZT drug fever is associated with high PCT levels. In these patients the highest PCT levels could be measured. Therefore, we conclude that PCT is not as specific for bacterial infections as previously thought. The presence of AZT hypersensitivity in older studies on RA patients was between $<1 \%$ and $5 \%$ [28]. The exact pathophysiological mechanisms of this idiosyncratic hypersensitivity reaction are unknown, but cytokine release, especially of TNFa, which stimulates PCT induction, has been proposed [29]. Davis et al., cited in [28], have suggested that imidazole moiety of AZT causes the allergic symptoms and the 6-mercaptopurine moiety the liver injury. Reintroduction of AZT should be avoided as this may lead to more serious reactions within hours of the re-challenge [30]. In summary, increased PCT may be induced by AZTassociated hypersensitivity and complicates the differential diagnosis of AAV flare versus infection.

\section{CONCLUSION}

In summary, our results from a cohort of 53 AAV patients demonstrate that the highly sensitive PCT assay (Thermo Scientific BRAHMS PCT sensitive KRYPTOR assay) is at a limit of $>0.1 \mathrm{ng} / \mathrm{ml}$ specific enough to reliably differentiate infection from vasculitis activity. PCT levels of active AAV patients in this cohort did not reach the reference limit defining systemic infections. The assay is even more sensitive in diagnosing local or mild systemic infections than the older assay generation (LUMItest). However, the clinician should be aware of the following hazards: 1) We presented cases with vasculitis and elevated PCT in the absence of infection due to a drug hypersensitivity reaction to AZT. 2) In the immunosuppressed patient PCT might be "false negative" despite infection due to a suppressed acute phase reaction which makes interpretation of borderline PCT $(0.06-0.5 \mathrm{ng} / \mathrm{ml})$ levels difficult without considering the clinical context.

The strength of the study lies in its standardized approach regarding assessment of disease activity and infection in our patients. However, the study has methodological limitations due to its retrospective approach and limited number of patients and the fact that we did not include patients with normal CRP levels. Nevertheless, the results with respect to the performance of the KRYPTOR assay are encouraging and should be validated in a larger and prospective cohort. 


\section{CONTRIBUTORS}

Concept and design: KH, FM, EC, JUH. Acquisition of data: $\mathrm{KH}$ and SS. Analysis and interpretation of data: $\mathrm{KH}$, SS, JUH, EC Drafting of the manuscript: all authors. Clinical revision of the manuscript and important intellectual content: all authors. Statistical analysis: KH.

\section{CONFLICT OF INTEREST}

The authors confirm that this article content has no conflict of interest.

\section{ACKNOWLEDGEMENTS}

We thank Dr. H.-J. Dreyer (Thermo Scientific, Germany) for organizational support regarding PCT measurements with Kryptor System.

Financial support was provided by Verein zur Förderung der Erforschung und Bekämpfung rheumatischer Erkrankungen Bad Bramstedt e.V. (Association for the promotion of research and treatment of rheumatic diseases $\mathrm{Bad}$ Bramstedt).

\section{REFERENCES}

[1] Assicot M, Gendrel D, Carsin H, Raymond J, Guilbaud J, Bohuon C. High serum procalcitonin concentrations in patients with sepsis and infection. Lancet 1993; 341: 515-8.

[2] Brunkhorst R, Eberhardt OK, Haubitz M, Brunkhorst FM. Procalcitonin for discrimination between activity of systemic autoimmune disease and systemic bacterial infection. Intensive Care Med 2000; 26(Suppl 2): S199-201.

[3] Moosig F, Csernok E, Reinhold-Keller E, Schmitt W, Gross WL. Elevated procalcitonin levels in active Wegener's granulomatosis. J Rheumatol 1998; 25: 1531-3.

[4] Zycinska K, Wardyn KA, Zielonka TM, Tyszko P, Straburzynski $\mathrm{M}$. Procalcitonin as an indicator of systemic response to infection in active pulmonary Wegener's granulomacytosis. J Physiol Pharmacol 2008; 59(Suppl 6): 839-44.

[5] Morath C, Sis J, Haensch GM, Zeier M, Andrassy K, Schwenger V. Procalcitonin as marker of infection in patients with Goodpasture's syndrome is misleading. Nephrol Dial Transplant 2007; 22: 2701-4.

[6] Chen D-Y, Chen Y-M, Ho W-L, Chen H-H, Shen G-H, Lan J-L. Diagnostic value of procalcitonin for differentiation between bacterial infection and non-infectious inflammation in febrile patients with active adult-onset Still's disease. Ann Rheum Dis 2009; 68: 1074-5.

[7] Okada Y, Minakami H, Tomomasa T, et al. Serum procalcitonin concentration in patients with Kawasaki disease. J Infect 2004; 48: 199-205.

[8] Wu J-Y, Lee S-H, Shen C-J, et al. Use of serum procalcitonin to detect bacterial infection in patients with autoimmune diseases: a systematic review and meta-analysis. Arthritis Rheum 2012; 64: 3034-42.

[9] Bonaci-Nikolic B, Jeremic I, Nikolic M, Andrejevic S, Lavadinovic L. High procalcitonin in a patient with drug hypersensitivity syndrome. Intern Med 2009; 48: 1471-4.

[10] Loock J, Lamprecht P, Gross WL. Acute inflammatory syndrome with elevated procalcitonin induced by mycophenolate sodium. J Rheumatol 2012; 39: 658-9.
[11] Watts R, Lane S, Hanslik T, et al. Development and validation of a consensus methodology for the classification of the ANCAassociated vasculitides and polyarteritis nodosa for epidemiological studies. Ann Rheum Dis 2007; 66: 222-7.

[12] Buhaescu I, Yood RA, Izzedine H. Serum procalcitonin in systemic autoimmune diseases--where are we now? Semin Arthritis Rheum 2010; 40: 176-83.

[13] Gilbert DN. Use of plasma procalcitonin levels as an adjunct to clinical microbiology. J Clin Microbiol 2010; 48: 2325-9.

[14] Steinbach G, Rau B, Debard A-L, et al. Multicenter evaluation of a new immunoassay for procalcitonin measurement on the Kryptor System. Clin Chem Lab Med 2004; 42: 440-9.

[15] Joo K, Park W, Lim M-J, Kwon S-R, Yoon J. Serum procalcitonin for differentiating bacterial infection from disease flares in patients with autoimmune diseases. J Korean Med Sci 2011; 26: 1147-51.

[16] Lacroix L, Manzano S, Galetto A, Gervaix A. Procalcitonin measurement for detection of serious bacterial infection in febrile children: comparison between two automated immunoassays. Clin Biochem 2012; 45: 593-5.

[17] De Kruif MD, Lemaire LC, Giebelen IA, et al. The influence of corticosteroids on the release of novel biomarkers in human endotoxemia. Intensive Care Med 2008; 34: 518-22.

[18] Lanoix JP, Bourgeois AM, Schmidt J, et al. Serum procalcitonin does not differentiate between infection and disease flare in patients with systemic lupus erythematosus. Lupus 2011; 20: 12530 .

[19] Kaczka K, Mikosiński S, Fendler W, Celnik A, Pomorski L. Calcitonin and procalcitonin in patients with medullary thyroid cancer or bacterial infection. Adv Clin Exp Med 2012; 21: 169-78.

[20] Matzaraki V, Alexandraki KI, Venetsanou K, et al. Evaluation of serum procalcitonin and interleukin-6 levels as markers of liver metastasis. Clin Biochem 2007; 40: 336-42.

[21] Paccolat C, Harbarth S, Courvoisier D, Irion O, de Tejada BM. Procalcitonin levels during pregnancy, delivery and postpartum. J Perinat Med 2011; 39: 679-83.

[22] Brodska H, Drabek T, Malickova K, et al. Marked increase of procalcitonin after the administration of anti-thymocyte globulin in patients before hematopoietic stem cell transplantation does not indicate sepsis: a prospective study. Crit Care 2009; 13: R37.

[23] Yüksel S, Ekim M, Ozçakar ZB, et al. The value of procalcitonin measurements in children with familial Mediterranean fever. Rheumatol Int 2012; 32: 3443-7.

[24] Meisner M, Tschaikowsky K, Hutzler A, Schick C, Schüttler J. Postoperative plasma concentrations of procalcitonin after different types of surgery. Intensive Care Med 1998; 24: 680-4.

[25] Maier M, Wutzler S, Lehnert M, et al. Serum procalcitonin levels in patients with multiple injuries including visceral trauma. J Trauma 2009; 66: 243-9.

[26] Carsin H, Assicot M, Feger F, et al. Evolution and significance of circulating procalcitonin levels compared with IL-6, TNF alpha and endotoxin levels early after thermal injury. Burns 1997; 23: 218-24.

[27] Sfia M, Boeckler P, Lipsker D. High procalcitonin levels in patients with severe drug reactions. Arch Dermatol 2007; 143: 1591.

[28] Jeurissen ME, Boerbooms AM, van de Putte LB, Kruijsen MW. Azathioprine induced fever, chills, rash, and hepatotoxicity in rheumatoid arthritis. Ann Rheum Dis 1990; 49: 25-7.

[29] Shaikh MM, Hermans LE, van Laar JM. Is serum procalcitonin measurement a useful addition to a rheumatologist's repertoire? A review of its diagnostic role in systemic inflammatory diseases and joint infections. Rheumatology (Oxford) 2015; 54: 231-40.

[30] Turow A, Yong TY, Fok JS, Li JYZ. Azathioprine hypersensitivity presenting as cardiogenic shock and Sweet's syndrome in a patient with microscopic polyangiitis. Intern Med 2012; 51: 1889-92. 